Article

\title{
Trees as a Shading System for Streets on the East-West Axis: Computer Simulations for the Selected Geometrical Proportions of Building Developments in Humid Continental Climate
}

\author{
Katarzyna Zielonko-Jung ${ }^{1}$ and Justyna Janiak ${ }^{2, *}$ (D) \\ 1 Department of Environmental Design, Faculty of Architecture, Gdańsk University of Technology, \\ Gabriela Narutowicza 11/12 Street, 80-233 Gdańsk, Poland; katarzyna.zielonko-jung@pg.edu.pl \\ 2 Faculty of Civil Engineering, Mechanics and Petrochemistry, Institute of Civil Engineering, \\ Warsaw University of Technology, 17 Łukasiewicza Street, 09-400 Płock, Poland \\ * Correspondence: justyna.janiak@pw.edu.pl
}

Received: 13 October 2019; Accepted: 2 December 2019; Published: 9 December 2019 updates

\begin{abstract}
The study is aimed at investigating the possibilities for solar protection provided to the street canyon located on the E-W axis and with the following profiles: shallow (height/width $(\mathrm{H} / \mathrm{W})$ $=0.2,0.6$, and 1$)$ and deep $(\mathrm{H} / \mathrm{W}=2)$ by two rows of trees located at a distance of $3 \mathrm{~m}$ away from southern and northern façades. The research was based on numerical simulation analyses conducted in the Rhinoceros ${ }^{\circledR}$ program, with the application of the Ladybug Tools environmental plugin for a street set in the city of Płock ( $\left.52^{\circ} 32^{\prime} 50^{\prime \prime} \mathrm{N} 19^{\circ} 42^{\prime} 00^{\prime \prime} \mathrm{E}\right)$ for the day characterized with the highest total intensity of insolation within the year, 7 June, between 8:00 a.m. and 5:00 p.m. The research yielded no differences in terms of shading the surface of the southern façade of streets with low, medium, and high building developments. However, slight differences $\left(40 \mathrm{~m}^{2}\right)$ were noted for the model with highrise building developments $(h=60 \mathrm{~m})$ characterized with a deep section $(H / W=2)$. The simulation also revealed that the $\mathrm{H} / \mathrm{W}$ ratio parameter only slightly $(0.88 \%-1.93 \%)$ affected the share trees have in shading the street floor, except in the case of very shallow profiles $(\mathrm{H} / \mathrm{W}=0.2)$.
\end{abstract}

Keywords: trees; shading; street canyon; insolation; sustainable design

\section{Introduction}

Insolation conditions that prevail in streets oriented towards the E-W axis, where the northern part of buildings is exposed to long-term insolation, can pose problems, both for users of the street open space as well as for residents of buildings that form the southern frontage. This may especially be the case during periods of intense solar radiation [1,2]. Most importantly, such conditions may lead to thermal discomfort [3] as well as to an increased demand for electricity to power air conditioning systems with which to cool down the overheated rooms. To improve the street microclimate and thermal conditions inside these buildings, it is advisable to apply solar control elements. In addition to various types of solar protection systems used to shade the façade and the ground (e.g., blinds, roofing), solutions that take advantage of greenery, especially trees, tend to be equally effective. (Trees provide effective protection against direct solar radiation. According to research by Konarska et al. [4], radiation transmittance for the deciduous trees tested in the full foliage period amounts to $8.8 \%-27.5 \%$.) For instance, studies by Givoni [5], Takács et al. [6], Ali-Toudert and Mayer [3], or Shashua-Bar and Hoffman [7] draw attention to the importance of highrise greenery as shading elements in the street space. Moreover, according to Mayer and Ali-Toudert [1], shading should be seen as the most effective climate function trees serve in improving thermal comfort. Highrise greenery applied as solar 
protection measures is particularly recommended for streets of shallow profiles (height/width $(H / W) \leq$ 1 ; the street height/width $(\mathrm{H} / \mathrm{W})$ parameter specifies the ratio of the layout geometry and is commonly applied in street space research [8]), irrespective of orientation. Whereas in the case of deep sections of streets $(H / W \geq 1)$, shading by trees is suggested mainly for the $E-W$ directed building development layouts [3].

In the research literature publications concerning the use of trees as shading elements in the street space, most frequently raised are issues related to the impact of plants on the microclimate. Studies are mainly devoted to the impact that high greenery exerts on air temperature (e.g., $[8,9])$ as well as to the impact greenery exerts on the pedestrian thermal balance (for instance, according to Ali-Toudert and Mayer [1], introducing trees into street space is likely to lower the physiological equivalent temperature (PET) index directly under tree crowns to $22 \mathrm{~K}$ ), e.g., [3,10-12]. The research mentioned above relates to the existing or virtual street models that vary in terms of orientation, building geometry, and climatic conditions, mainly such conditions that can lead to thermal discomfort for residents of these zones, for example, Mediterranean continental climate zones (Csa) (the climatic condition classification, according to Köppen.) [1].

However, there is a lack of analysis regarding strictly the changes in street shaded surface provided by trees, given various heights and spatial relations of building developments that form street frontages. Conditions of street insolation, shaped by factors to include the very building developments, can justify the application of highrise greenery to protect the façade as well as the area from direct solar radiation. An analysis of streets marked with diverse geometries expressed by the $\mathrm{H} / \mathrm{W}$ ratio parameter will also make it possible to indicate areas for which green shading elements can be the only or additional protection against direct solar radiation.

The following study is predominantly aimed at assessing the applicability of the selected greenery arrangement (i.e., two individual rows of deciduous trees located at a distance of three meters away from the northern and southern frontage), in the street located on the E-W axis, given the changing shading conditions created by building developments of varying heights. A fixed distance between frontages was selected for the study, that is, a $30 \mathrm{~m}$ distance in the lines demarking the street and 4 variants of building developments: low, medium, high, and highrise developments (classification of buildings into height-defined groups was done according to the Regulation of the Minister of Infrastructure of 12 April 2002 on technical conditions to be met by buildings and their localisation [13]). Each of the models presents a different street section, ranging from a very shallow street section, with a H/W parameter of 0.2 , to a deep street section, with a H/W ratio of 2 . Studies of the selected four profile variants have enabled the researchers to approximate the impact of E-W-oriented city street geometry on the possibility to apply highrise green elements as shading measures that would operate in the summer season. An analysis and comparison of the floor and wall surface $\mathrm{s}\left(\mathrm{m}^{2}\right)$ of the street canyon (a street canyon is a simplified vertical street profile; the term is commonly applied in the context of urban climate research as the basic structural unit with which to describe urban space [1].) were conducted for four reference models (i.e., models devoid of any greenery whatsoever and those shaded by rows of trees for all the cases considered) for the day with the highest solar radiation intensity, namely 7 June. Moreover, the hours and duration of shading (h) were also verified in the study. Insolation conditions prevailing in the city of Płock, Poland, in the humid continental climate zone were selected for the simulation.

\section{Materials and Methods}

The analyses were performed with the use of a computer simulation method. The chosen method makes it possible to replicate the insolation conditions for a street canyon situated on the E-W axis with an alteration to the building height while retaining spatial relationships between architectural and plant elements and leaving greenery parameters unchanged. The Rhinoceros ${ }^{\circledR}$ program version 6 (Robert McNeel \& Associates, Barcelona, Spain), with integrated algorithm editor, Grasshoper, and parametric environmental plugin, Ladybug, was used. The selected tools are based on the well-tried EnergyPlus 
(U.S. Department of Energy's (DOE) Building Technologies Office (BTO), Washington, DC, USA), and Radiance (Regents of the University of California, California, CA, USA), and Daysim software, all of which provide a chance to conduct such studies as daylight analyses inside buildings and around them. The research used the sunlight hours analysis algorithm, which determines the number of hours in which direct sunlight is received by the test object in a given time, which enables shading analysis for a selected time interval.

The street model created for the needs of the study consisted of buildings, arranged in a row, which constituted a $40 \mathrm{~m}$, dense building development line oriented along the long $\mathrm{E}-\mathrm{W}$ axis. The street selected for testing was $30 \mathrm{~m}$ wide in the boundary lines, with parameters corresponding to the collective road and the main one-carriageway street [14]. Four variants of the street model with building developments were taken into consideration: low developments $(h=6 \mathrm{~m})$, medium developments $(h=18 \mathrm{~m})$, high developments $(\mathrm{h}=30 \mathrm{~m})$, and highrise developments $(\mathrm{at} h=60 \mathrm{~m})$. Table 1 presents the characteristic geometry parameters of different versions of the street canyon, including $\mathrm{H} / \mathrm{W}$ ratios. The height/width parameters adopted for the study will provide a chance to examine the shaded surface, both in a deep street canyon with $\mathrm{H} / \mathrm{W}=2$ as well as the shallow street canyon, with $\mathrm{H} / \mathrm{W}=1,0.6$, and 0.2 .

Table 1. Characteristic parameters of the E-W-oriented street model used in the simulation.

\begin{tabular}{cccccc}
\hline $\begin{array}{c}\text { Height/Width } \\
\text { (H/W) }\end{array}$ & Length (m) & Width $(\mathbf{m})$ & $\begin{array}{c}\text { Building } \\
\text { Height }(\mathbf{m})\end{array}$ & $\begin{array}{c}\text { Horizontal } \\
\text { Surface }\left(\mathbf{m}^{2}\right)\end{array}$ & $\begin{array}{c}\text { Façade Surface } \\
\text { of the 1st } \\
\text { Street } \\
\left.\text { Frontage } \mathbf{( m}^{2}\right)\end{array}$ \\
\hline 2 & 40 & 30 & 60 & 1200 & 2400 \\
1 & 40 & 30 & 30 & 1200 & 1200 \\
0.6 & 40 & 30 & 18 & 1200 & 720 \\
0.2 & 40 & 30 & 6 & 1200 & 240 \\
\hline
\end{tabular}

The buildings were modelled as cuboid forms, devoid of windows and door openings or other architectural details, not including material solutions. The adopted simplifications are consistent with the purpose of the research, for which geometry and location provide crucial factors in the context of building developments.

Individual rows of trees, $34 \mathrm{~m}$ in length, located along the northern and southern street frontage, at a distance of $3 \mathrm{~m}$ away from the façade (Figure 1), provided the form of greenery selected for the study. The selected distance between plants and the building development under research resulted from the analysis of the location of trees in a street space that was suitable for vehicle traffic, as well as from previous research conducted by the authors. (The distance was selected on the basis of prior research conducted by the authors regarding the analysis of the possibilities to shade the southern facades of buildings that form a street located towards the E-W axis by implementing a parallel single row of trees, close to the frontage.) Each of the green alleys consisted of 6 trees set at every $6 \mathrm{~m}$.

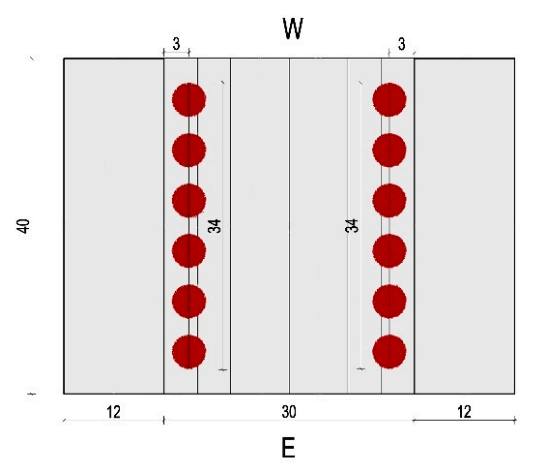

Figure 1. Location of two rows of trees in a street on the E-W axis, modelled for the needs of simulation. 
One tree species was selected for the study, namely Acer pseudoplatanus, which performs well in a highly urbanized environment and is, therefore, commonly applied to cover streets, parking lots, and residential greenery in European cities $[15,16]$. In the simulation, representatives of this species 20-25 years old were applied, whose circumference equaled $0.44 \mathrm{~m}$. The remaining parameters of the trees have been presented in Table 2 .

Table 2. The main parameters of the tree model selected and applied for the needs of simulation. Data based on [16-18].

\begin{tabular}{cc}
\hline Characteristics & Acer pseudoplatanus \\
\hline Trunk circumference & $0.44 \mathrm{~m}$ \\
Tree crown width & $4 \mathrm{~m}$ \\
Tree crown height & $5 \mathrm{~m}$ \\
Tree crown shape & Oval \\
Tree height & $2 \mathrm{~m}$ \\
Tree height from its base to its crown & $7 \mathrm{~m}$ \\
Leaf area index (LAI) & 6 \\
\hline
\end{tabular}

The selected greenery model developed on the behalf of the simulation consisted of two basic parts presented in a simplified form (i.e., the trunk, which was represented by a cylinder $0.14 \mathrm{~m}$ in diameter and $2.0 \mathrm{~m}$ in height, and a tree crown). The crown was presented as a set of randomly oriented and localized leaves, whereas the set of branches, twigs, or shoots was unmarked. The irregular maple leaves with five lobes were modelled as straight planes, circular in shape, and whose surface was similar to the original. Together, the elements formed the shape of a flattened sphere. The number of planes was chosen in such a way as to make the leaf area index (LAI), defined as the ratio of the one-sided leaf surface to the shaded ground surface, equal 6. (For trees 5 to $10 \mathrm{~m}$ in height, LAI equals about 7 [14]; therefore, for the greenery model with a height of $7 \mathrm{~m}$, a coefficient equal to 6 was adopted.) The adopted modelling method of trees accounted for the most vital parameters of greenery to act as shading elements, that is, the crown habit, size, and crown shape (according to research by Armson et al. [19], the density, size, and shape of the crown are important for shading. Trees with a lower proportion coefficient tend to shield surfaces from direct solar radiation for longer timespans. In turn, according to Mayer and Ali-Toudert [1], the shape and volume of the tree crown may be more important for the shaded surface than the density.), while at the same time introducing the necessary simplifications resulting from the limitations of the available computer hardware.

\section{Results}

The research was conducted for a street canyon located in the humid continental climate zone in the example of the city of Płock ( $52^{\circ} 32^{\prime} 50^{\prime \prime} \mathrm{N} 19^{\circ} 42^{\prime} 00^{\prime \prime} \mathrm{E}$; $58-105 \mathrm{~m}$ a.s.l.). The selected city is located in the center of Poland where total solar radiation is one of the highest in the country [20]. Moreover, in Poland, according to the study by Błażejczyk et al. [20], a further increase in total solar radiation is forecasted (solar radiation in summer months in Poland will increase from 1676-1678 $\mathrm{MJ} \cdot \mathrm{m}^{-2}$ in $2021-2030$ to $1730-1737 \mathrm{MJ} \cdot \mathrm{m}^{-2}$ in the last decade of the century [20].). Hence, it is advisable to search for various types of solutions that will provide protection against intense insolation for spaces also in this latitude. The simulation was conducted for the day with the highest intensity of direct solar radiation to fall on the horizontal surface for the selected area, which was 7 June. A $9 \mathrm{~h}$ time interval from 8:00 a.m. to 5:00 p.m. was analyzed and was also divided into hourly intervals (8:00-9:00, etc.). Limiting the simulation to one day allowed for an accurate analysis of insolation and shaded surfaces in the street space with different variants of its geometry.

The analysis proved the need for solar protection of the south-oriented street frontage and, partly, also of the ground in the street boundary lines, especially in case of low $(\mathrm{H} / \mathrm{W}=0.2)$, medium $(\mathrm{H} / \mathrm{W}=0.6)$, and high $(\mathrm{H} / \mathrm{W}=1)$ building developments (Table 3$)$. In each of these cases, the northern part of the street canyon experienced full solar exposure throughout the simulation period, 
which was for $9 \mathrm{~h}$. The results obtained in the study confirmed the conclusions contained in the work of Ali-Toudert and Mayer [3], according to whom it is necessary to introduce shading elements in the spaces of streets with $\mathrm{H} / \mathrm{W} \leq 1$, also in case of buildings located on the $\mathrm{E}-\mathrm{W}$ axis.

Table 3. Total shaded surface of the street canyon floor and walls by building developments located on the E-W axis at selected H/W parameters for 7 June between 8:00 a.m. and 5:00 p.m. for the city of Płock, Poland.

\begin{tabular}{cccccc}
\hline H/W & $\begin{array}{c}\text { Total Shaded } \\
\text { Surface of the } \\
\text { Northern } \\
\text { Façade by } \\
\text { Building } \\
\text { Developments } \\
\left(\mathbf{m}^{2} \mathbf{\%} \text { of the }\right. \\
\text { Area) }\end{array}$ & $\begin{array}{c}\text { Total Shaded } \\
\text { Surface of the } \\
\text { Southern } \\
\text { Façade by } \\
\text { Building } \\
\text { Developments } \\
\left(\mathbf{m}^{2} \mathbf{\%} \text { of the }\right. \\
\text { Area) }\end{array}$ & $\begin{array}{c}\text { Total Shaded } \\
\text { Surface of the } \\
\text { Street Canyon } \\
\text { Floor by } \\
\text { Building } \\
\text { Developments } \\
\left(\mathbf{m}^{2} \mathbf{\%} \text { of the }\right. \\
\text { Area) }\end{array}$ & $\begin{array}{c}\text { Shading Time } \\
\text { of the Street } \\
\text { Canyon Walls } \\
\text { by Building } \\
\text { Developments } \\
\text { (h) }\end{array}$ & $\begin{array}{c}\text { Shading Time } \\
\text { of the Street } \\
\text { Canyon Floor } \\
\text { by Building } \\
\text { Developments } \\
\text { (h) }\end{array}$ \\
\hline 2 & $\begin{array}{c}2400,100 \% \\
1200,100 \%\end{array}$ & $294.07(12.25 \%)$ & $100 \%$ & 4 & 9 \\
0.6 & $720,100 \%$ & $0 \%$ & $57.29 \%$ & 0 & 9 \\
0.2 & $240,100 \%$ & $0 \%$ & $34.00 \%$ & 0 & 9 \\
\hline
\end{tabular}

The simulation proved that for street variants of shallow sections (i.e., with $\mathrm{H} / \mathrm{W}$ parameters of 0.2 and 0.6 ), at least $66 \%$ to about $88 \%$ of the floor area remained unshaded in the analyzed period of time, which in real-life conditions can significantly affect the thermal comfort of users of these spaces exposed to solar radiation. Similarly, for tall buildings $(\mathrm{h}=30 \mathrm{~m})$ that form a dense street building development line with an $\mathrm{H} / \mathrm{W}$ ratio equal to 1 , in which case the buildings only shaded the floor throughout the simulation, the unshaded area amounted from $6 \%$ to a maximum of $55 \%$.

Given the height of buildings ranging from 6 to $30 \mathrm{~m}$, a lack in shading of the southern frontage was noted in the study. On the other hand, shading conditions formed by the highrise building developments (with $\mathrm{h}=60 \mathrm{~m}$ ) within the street canyon of $\mathrm{H} / \mathrm{W}=2$ ratio provided partial shading to the south-facing façades within 4 out of 9 simulation hours (about $12 \%$ of the wall area in total). In this case, solar protection for the south-facing parts of the walls, up to the height of $6 \mathrm{~m}$, was partly provided by the opposite building development, whereas all remaining shading elements could serve as supportive solutions. A similar situation was observed in the case of the canyon floor of a deep-profile street $(\mathrm{H} / \mathrm{W}$ $=2$ ), whose surface, in total, received $100 \%$ protection against direct solar radiation by the surrounding buildings throughout the $9 \mathrm{~h}$ studied.

The research failed to prove any differences in terms of shaded surface of southern façades provided by a given arrangement of greenery within the space of $\mathrm{E}-\mathrm{W}$ oriented streets built up with low, medium, and high building developments (with max. H/W =1) (Table 4). In turn, the shading ability of all the trees did not take full advantage of the street space with highrise building developments $(\mathrm{h}=60 \mathrm{~m}$ ), whose height-to-width ratio equaled 2. In this case, the research has revealed a decrease of nearly 1.5 times with respect to the shaded surface provided to the southern frontage, as compared to other street geometries under consideration. Additionally, the minimum surface area of walls shaded by trees was 6 times smaller than that of a street canyon lined with low building developments (with $\mathrm{h}=6 \mathrm{~m}$ ). On the other hand, trees applied as the shading elements to cover the southern façades at the ground floor level (the model assumed a ground floor height of $3 \mathrm{~m}$ up from ground level) tended to provide protection against direct solar radiation of up to $90 \%$ in total for all considered $\mathrm{H} / \mathrm{W}$ parameters throughout the entire simulation period (Table 5). However, within the $9 \mathrm{~h}$ of the research, the surface of the ground floor walls in the northern part of the street canyon, whose ratio of $\mathrm{H} / \mathrm{W}$ equaled 2 , received $100 \%$ protection against insolation, taking into account shading by the building development situated opposite to the canyon. 
Table 4. The shaded surface of the south-oriented frontage of buildings varying in heights by a row of trees set $3 \mathrm{~m}$ away from the buildings, in the street located on the E-W axis on 7 June between 8:00 a.m. and 5:00 p.m.

\begin{tabular}{cccccc}
\hline H/W & $\begin{array}{c}\text { Building } \\
\text { Heights } \mathbf{( m )}\end{array}$ & $\begin{array}{c}\text { Minimum } \\
\text { Shade Surface } \\
\mathbf{( m}^{\mathbf{2}} \mathbf{)}\end{array}$ & $\begin{array}{c}\text { Maximum } \\
\text { Shade Surface } \\
\mathbf{( m}^{2} \mathbf{)}\end{array}$ & $\begin{array}{c}\text { Shade Surface } \\
\text { in Total }\left(\mathbf{m}^{2} \mathbf{)}\right.\end{array}$ & $\begin{array}{c}\text { \% Total Façade } \\
\text { Shaded } \\
\text { Surface }\end{array}$ \\
\hline 2 & 60 & 3.10 & 55.38 & 79.89 & $3.33 \%$ \\
1 & 30 & 19.72 & 59.00 & 119.76 & $9.98 \%$ \\
0.6 & 18 & 18.57 & 58.53 & 119.56 & $16.61 \%$ \\
0.2 & 6 & 18.57 & 61.53 & 119.56 & $49.82 \%$ \\
\hline
\end{tabular}

Table 5. The shaded surface of the ground floor façade with an area of $120 \mathrm{~m}^{2}$ being a part of south-facing frontage developed in a street with varying $\mathrm{H} / \mathrm{W}$ ratio parameters provided by a row of trees set $3 \mathrm{~m}$ away from the building on 7 June between 8:00 a.m. and 5:00 p.m.

\begin{tabular}{cccccc}
\hline H/W & $\begin{array}{c}\text { Building } \\
\text { Heights } \mathbf{( m )}\end{array}$ & $\begin{array}{c}\text { Minimum } \\
\text { Shade Surface } \\
\mathbf{( m}^{2} \mathbf{)}\end{array}$ & $\begin{array}{c}\text { Maximum } \\
\text { Shade Surface } \\
\left.\mathbf{( m}^{2}\right)\end{array}$ & $\begin{array}{c}\text { Shade Surface } \\
\text { in Total }\left(\mathbf{m}^{2} \mathbf{)}\right.\end{array}$ & $\begin{array}{c}\text { Total } \\
\text { Ground Floor } \\
\text { Facade Shaded } \\
\text { Surface }\end{array}$ \\
\hline 2 & 60 & 2.97 & 55.38 & 110.19 & $91.83 \%$ \\
1 & 30 & 19.72 & 56.68 & 113.24 & $94.37 \%$ \\
0.6 & 18 & 18.57 & 56.48 & 113.24 & $94.37 \%$ \\
0.2 & 6 & 18.57 & 56.48 & 113.24 & $94.37 \%$ \\
\hline
\end{tabular}

In all the variants under research, the modification in the height of building developments, including the $\mathrm{H} / \mathrm{W}$ parameter of the street on the $\mathrm{E}-\mathrm{W}$ axis, exerted the greatest impact on the insolation of the street canyon floor. As the data presented in Table 6 indicate, two rows of trees can provide additional solar protection for more than $10 \%$ of the canyon floor surface for all considered $\mathrm{H} / \mathrm{W}$ variants, whereby protection against direct solar radiation for the area located within boundary lines for the street on the $\mathrm{E}-\mathrm{W}$ axis is primarily provided by greenery planted along the south-facing frontage. However, in the case of the street model built-up with low $(\mathrm{H} / \mathrm{W}=0.2)$, medium $(\mathrm{H} / \mathrm{W}=0.6)$, and high $(\mathrm{H} / \mathrm{W}=1)$ building developments, trees (in the conditions adopted for analysis) were efficient in shading against insolation in the precise area that received no shading from the surrounding building developments throughout the simulation. In this case, the high greenery planted in the northern part of the street provided additional shading at levels from $13.36 \%$ to $27.88 \%$ of the street canyon floor that was exposed to the solar radiation. However, the trees provided a greater area of shading for the floor surface than did the surrounding building development (over $70 \%$ of the total shading of the street canyon floor) solely in case of the variant built-up with low building developments, whose parameter $\mathrm{H} / \mathrm{W}=0.2$, with the considered arrangement of greenery. In this case, two rows of Acer pseudoplatanus covered almost $1 / 3$ of the street surface. For systems with medium $(\mathrm{H} / \mathrm{W}=0.6)$ and high $(\mathrm{H} / \mathrm{W}=1)$ building developments, differences in area within street boundary lines shaded by trees were insignificant and equaled less than $1 \%(0.88 \%$ exactly). On the other hand, between the street model of a deep $(\mathrm{H} / \mathrm{W}=2)$ and a shallow profile $(\mathrm{H} / \mathrm{W}=0.2)$, changes in the surface protected against direct solar radiation reach up to $14.83 \%$. The research also yielded results concerning the fact that a twofold increase in the street geometry proportion, with $\mathrm{H} / \mathrm{W}$ equal to 2 rather than 1, caused only a slight decrease in the shaded surface of the canyon floor by high greenery, namely at a level of about a 1.1 decrease. 
Table 6. The shaded surface of the floor of the street canyon located on the E-W axis with varying $H / W$ parameters by a row of trees set $3 \mathrm{~m}$ away from the building on 7 June between 8:00 a.m. and 5:00 p.m.

\begin{tabular}{|c|c|c|c|c|c|c|}
\hline $\mathrm{H} / \mathrm{W}$ & $\begin{array}{c}\text { Minimum } \\
\text { Tree } \\
\text { Shading } \\
\text { Surface }\left(\mathbf{m}^{2}\right)\end{array}$ & $\begin{array}{c}\text { Maximum } \\
\text { Tree } \\
\text { Shading } \\
\text { Surface }\left(\mathbf{m}^{2}\right)\end{array}$ & $\begin{array}{c}\text { Tree } \\
\text { Shading } \\
\text { Surface in } \\
\text { Total }\left(\mathrm{m}^{2}\right)\end{array}$ & $\begin{array}{l}\text { \% of Total } \\
\text { Shaded } \\
\text { Surface of } \\
\text { the Floor by } \\
\text { Trees }\end{array}$ & $\begin{array}{l}\text { Shading by } \\
\text { Trees of the } \\
\text { Floor } \\
\text { Surface } \\
\text { beyond the } \\
\text { Building } \\
\text { Development } \\
\text { Shade }\end{array}$ & $\begin{array}{c}\text { Total Floor } \\
\text { Surface } \\
\text { Shaded by } \\
\text { Building } \\
\text { Developments } \\
\text { and by Trees } \\
\left(\mathrm{m}^{2}\right)\end{array}$ \\
\hline 2 & 2.40 & 206.04 & 156.64 & $13.05 \%$ & - & 1200 \\
\hline 1 & 52.88 & 205.20 & 169.23 & $14.10 \%$ & 160.32 & 847.76 \\
\hline 0.6 & 52.88 & 212.52 & 179.72 & $14.98 \%$ & 160.32 & 568.32 \\
\hline 0.2 & 137.84 & 221.64 & 334.56 & $27.88 \%$ & 334.56 & 470.56 \\
\hline
\end{tabular}

The analyses conducted for the sake of the study revealed that, for all the considered variants of street models covered with buildings of varying heights, the southern frontage façades were shaded for 8 out of $9 \mathrm{~h}$ of the simulation period. For the timespan under consideration, rows of Acer pseudoplatanus were efficient in covering the street canyon floor exclusively between 4:00 and 5:00 p.m. In the course of the study, differences between building models with parameters $\mathrm{H} / \mathrm{W} \leq 1$ and $\mathrm{H} / \mathrm{W}$ equal to 2 were observed in terms of the specific hour at which the maximum shading of southern façade walls by high greenery occurred. For a deep profile street $(\mathrm{H} / \mathrm{W}=2)$, the trees provided maximum coverage between 2:00 and 3:00 p.m., whereas in cases of other street profiles, maximum coverage was between 1:00 and 2:00 p.m. The simulation revealed as well that for a street canyon with highrise building developments $(\mathrm{H} / \mathrm{W}=2)$, trees provided additional solar protection between 10:00 a.m. and 2:00 p.m., at which time the southern frontage was partly shaded by the building developments (Figure 2). However, from 11:00 a.m. to 2:00 p.m., shading provided by the building development located opposite tended to be greater than that offered by plants applied to serve the shading function, with the greatest scope of difference amounting to $257.20 \mathrm{~m}^{2}$ at the time between 12:00 p.m. and 1:00 p.m.

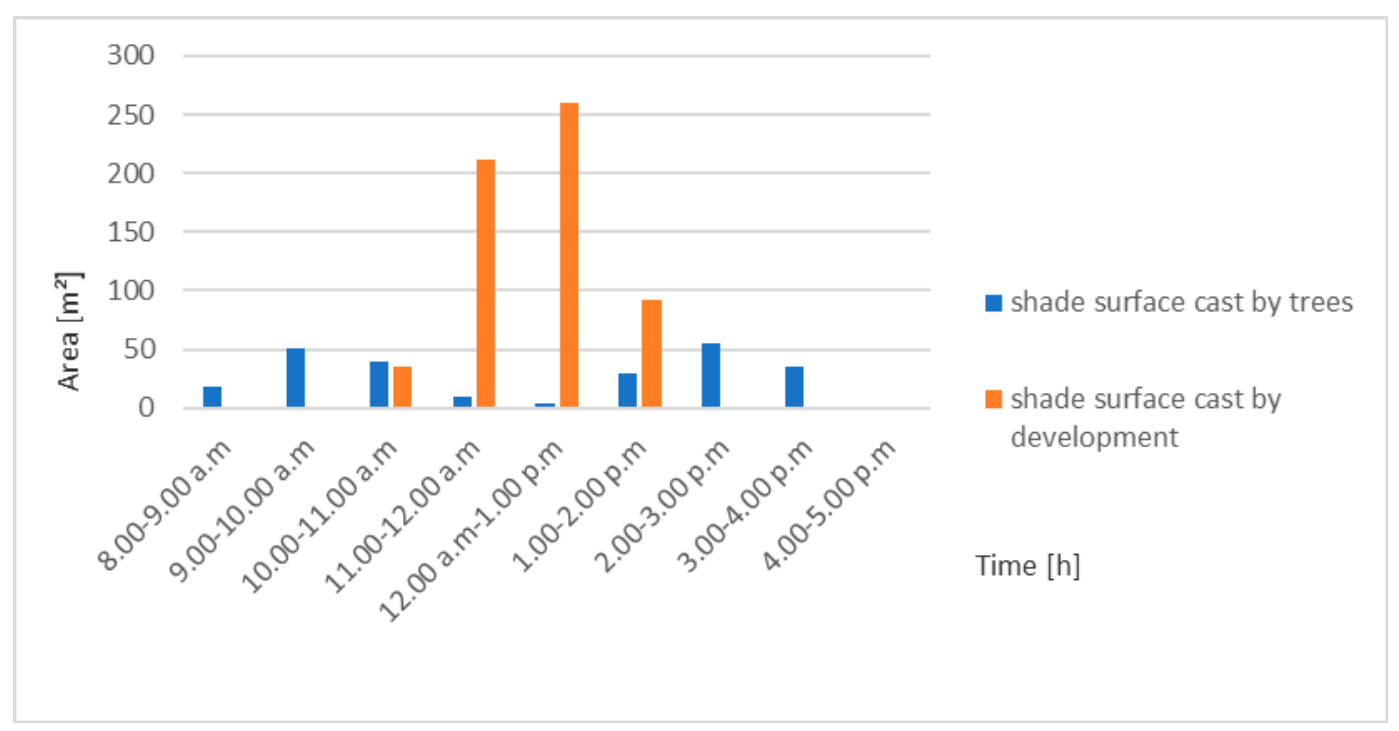

Figure 2. Shaded surface provided to the south-facing frontage by a row of trees planted at a distance of $3 \mathrm{~m}$ away from the façade and by the building developments located opposite, on the day of 7 June between 8:00 a.m. and 5:00 p.m. in the street located on the E-W axis, whose $\mathrm{H} / \mathrm{W}$ parameter is equal to 2 . 
On the other hand, the part trees took in the shading of the canyon floor surface was greater than the shaded surface provided by building developments only for 1 out of $9 \mathrm{~h}$ of the simulation period (i.e., from 4:00 p.m. to 5:00 p.m.) for all frontage heights variants tested (Figures 3 and 4). The greatest differences in terms of the shaded surface in the boundary lines of the street in the area between the greenery and the buildings were recorded in the timespan between 11:00 a.m. and 2:00 p.m. However, for a street marked with a deep profile $(\mathrm{H} / \mathrm{W}=2)$, the greatest difference (12:00 to 1:00 p.m.) was 1.8 times more significant than that of the difference observed in the case of the model with the $\mathrm{H} / \mathrm{W} \leq 1$ parameter (Figure 4 ).

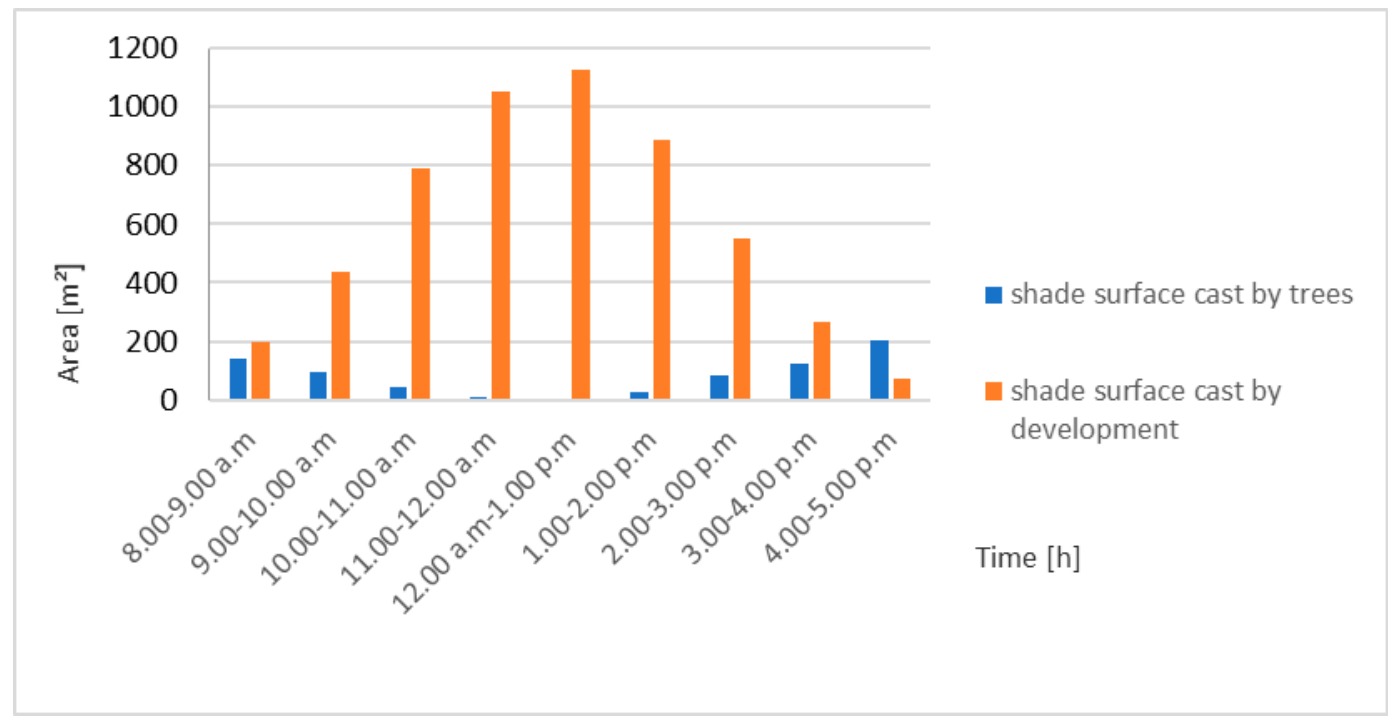

Figure 3. Shaded surface provided to the floor of the street canyon located on the E-W axis, whose H/W parameter is equal to 2 by a row of trees planted at a distance of $3 \mathrm{~m}$ away and by the building developments located opposite, on the day of 7 June between 8:00 a.m. and 5:00 p.m.

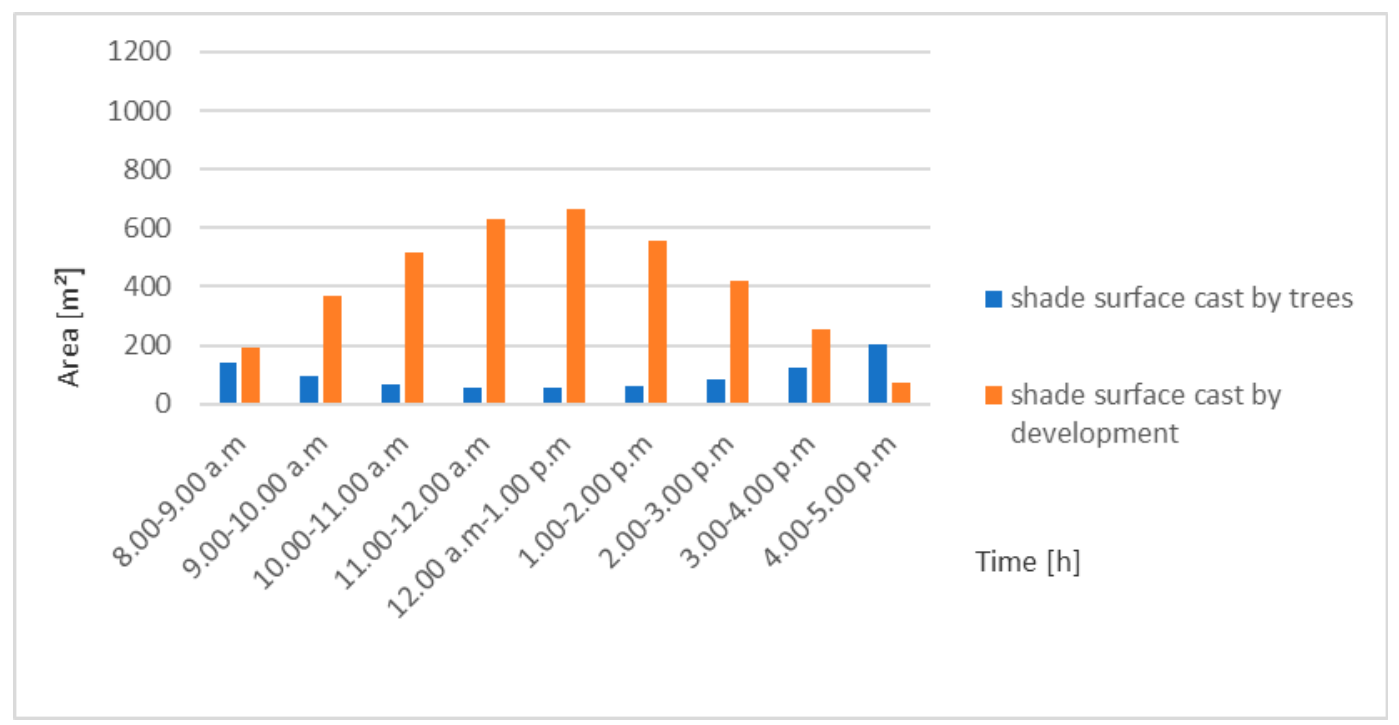

Figure 4. The shaded surface of the floor of the street canyon located on the E-W axis, marked with $\mathrm{H} / \mathrm{W}=1$, by a row of trees planted $3 \mathrm{~m}$ away from the façade and by the opposite building development on 7 June between 8:00 a.m. and 5:00 p.m.

At the time when the highest degree of total direct radiation intensity on the horizontal surface occurred, which was from 9:00 a.m. to 10:00 a.m., for the model where the $\mathrm{H} / \mathrm{W}$ ratio parameter equaled $0.2(15.57 \%)$, the shaded surface of the canyon floor by high greenery amounted to almost 
twice the surface obtained in the remaining variants tested, for which $\mathrm{H} / \mathrm{W} \geq 0.6$ (7.75\%) (Figure 5). In addition, streets with low building developments were the only cases to experience almost twice as high a share of trees in shading the areas between the street boundary lines than in the case for the remaining building developments. Hence, in a street whose parameter $\mathrm{H} / \mathrm{W}=0.2$, the use of greenery as shading elements can be a key protection measure against direct solar radiation for the street canyon floor surface.

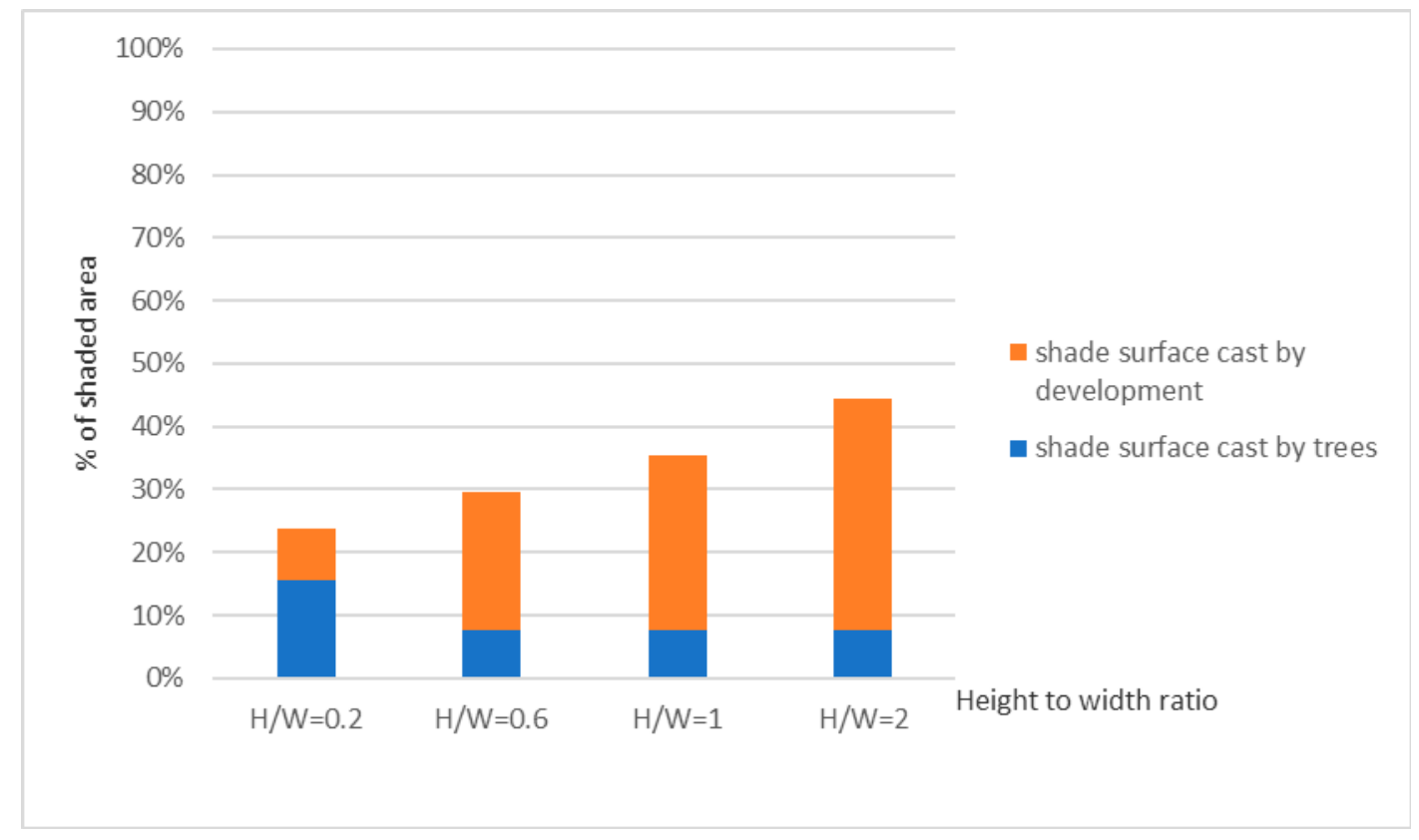

Figure 5. The shaded surface of the floor of the street canyon located on the E-W axis by two rows of trees and the opposite building development on 7 June at the time of the highest total insolation intensity, which was 9:00 a.m. to 10:00 a.m., depending on the value of the $\mathrm{H} / \mathrm{W}$ parameter.

\section{Discussion}

The results obtained from simulation for variants of the average-width street built-up with low, medium, high, and high-rise developments, oriented on the E-W axis, provide rationale for the introduction of additional shading elements along the southern frontage in all the cases considered. These conclusions are consistent with other works, including Ali-Toudert and Mayer [3], who draw attention to the need for additional solar protection measures to be implemented in street canyons located on the E-W axis. However, in street models of shallow profiles, namely with the $\mathrm{H} / \mathrm{W} \leq 1$, high greenery was the only form of protection against insolation for the northern part of the layout, including both the ground and the façade, throughout the entire analyzed timespan (8:00 a.m. to 5:00 p.m.). For these cases, trees are an important element to improve urban thermal comfort resulting from shading the surfaces which are exposed to the sun for a long time. (Shading by trees is responsible for about $80 \%$ of the cooling effect, and it reduces thermal stress more than evapotranspiration [1].) In turn, for a street built-up with high-rise building developments $(\mathrm{H} / \mathrm{W}=2)$, the selected tree species (20-25 year-old Acer pseudoplatanus) constitute a supplementary shading element for the surrounding buildings for almost half of the simulation period, which was $4 \mathrm{~h}$. At the same time, the use of high-rise greenery for protection against direct solar radiation brings a number of other important benefits, such as the reduction of air temperature by evapotranspiration or psychological and social functions [21]. In addition, the use of trees in the street space on the E-W axis results in a lower demand for electricity to power air conditioning systems with which to cool down the interiors of the southern frontages buildings, especially those on the ground floor level in all analyzed variants of the model geometry. 
Among the considered cases, street geometry located towards the $\mathrm{E}-\mathrm{W}$ direction, whose $\mathrm{H} / \mathrm{W}$ ratio parameter did not exceed 1, failed to influence the shaded surface provided to the southern façades by the greenery form selected for testing. However, only in the case of streets with a deep section $(\mathrm{H} / \mathrm{W}=2)$ built-up with high-rise building developments $(\mathrm{h}=60 \mathrm{~m})$ did trees display a less significant share in the southern frontage shading (by almost $40 \mathrm{~m}^{2}$ ). The height and spatial relationships between the buildings that form the E-W-oriented street frontages exert an insignificant impact on the extent of shading provided to the area by rows of trees $(0.88-1.93 \%)$. Streets with very shallow profiles (with $\mathrm{H} / \mathrm{W}=0.2$ ) are, however, an exception to the above conclusion, and in such cases, it is recommended to maintain the minimum required distance between trees in the line or to use broadleaf species like Acer pseudoplatanus [9].

The study made it possible to define the possibilities of applying trees for solar protection of streets located on the E-W axis, with a variety of geometries and spatial correlations between building developments. As the analysis proved, high greenery applied as a shading element can be widely implemented in case of $\mathrm{E}-\mathrm{W}$-oriented streets with various $\mathrm{H} / \mathrm{W}$ ratio parameters. The simulation presented the potential of greenery as a shading element in a street canyon with different geometries for one selected day in the period with the highest intensity of solar radiation. For a detailed analysis of the use of greenery in streets with buildings of different heights, it is advisable to conduct further studies with a longer time horizon. In light of the results obtained, it is worth paying attention to factors that can shape the shading possibilities of high greenery to a greater extent than the specifics of the E-W-oriented street geometry, such as spatial correlations between trees and the building development or plant parameters.

Author Contributions: Conceptualization, K.Z.-J. and J.J.; methodology, K.Z.-J. and J.J.; software, J.J.; validation, K.Z.-J. and J.J.; formal analysis, K.Z.-J. and J.J.; investigation, J.J.; resources, J.J.; data curation, J.J.; writing - original draft preparation, K.Z.-J. and J.J.; writing - review and editing K.Z.-J. and J.J.; visualization, J.J., supervision K.Z.-J.

Funding: This research received no external funding.

Conflicts of Interest: The authors declare no conflict of interest.

\section{References}

1. Mayer, H.; Ali-Toudert, F. Thermal comfort in urban street with trees under hot summer conditions. In Proceedings of the 22nd Conference on Passive and Low Energy Architecture (PLEA), Beirut, Lebanon, November 2005; Available online: researchgate.net/publication/261135276_Thermal_comfort_in_urban_ streets_with_trees_under_hot_summer_conditions (accessed on 5 March 2019).

2. Emmanuel, R.; Rosenlund, H.; Johansson, E. Urban shading-A design option for the tropics? A study in Colombo, Sri Lanka. Int. J. Climatol. 2007, 37, 1847-2015. [CrossRef]

3. Mayer, H.; Ali-Toudert, F. Effects of Street Design on Outdoor Thermal Comfort. 2006. Available online: www. researchgate.net/publication/242157021_Effects_of_Street_Design_on_Outdoor_Thermal_Comfort (accessed on 10 May 2019).

4. Konarska, J.; Lindberg, F.; Larsson, A.; Thorsson, S.; Homler, B. Transmissivity of solar radiation through crowns of single urban trees-application for outdoor thermal comfort modelling. Theor. Appl. Climatol. 2014, 117, 363-376. [CrossRef]

5. Givoni, B. Impact of Green Areas on site and urban Climates. In Climate Considerations in Building and Urban Design; Degenhardt, J., Ed.; Van Nostrand Reinhold: New York, NY, USA, 1998; pp. 303-331.

6. Takács, A.; Kiss, M.; Gulyás, A.; Tanács, E.; Kántor, N. Solar permeability of Different Tree Species in Szeged, Hungary. Geogr. Pannonica 2016, 20, 32-41. [CrossRef]

7. Shashua-Bar, L.; Hoffman, M.E. Vegetation as a climatic component in the design of an urban street An empirical model for predicting the cooling effect of urban green areas with trees. Energy Build. 2000, 31, 221-235. [CrossRef]

8. Arnfield, A.J. Street Design and Urban Canyon Solar Access. Energy Build. 1990, 14, 117-131. [CrossRef] 
9. Shashua-Bar, L.; Potcher, O.; Bitan, A.; Boltansky, D.; Yaakov, Y. Microclimate modelling of street tree species effects within the varied urban morphology in the Mediterranean city of Tel Aviv, Israel. Int. J. Climatol. 2010, 30, 44-57. [CrossRef]

10. Shashua-Bar, L.; Pearlmutter, D.; Erell, E. The influence of trees and grass on outdoor thermal comfort in a hot-arid environment. Int. J. Climatol. 2011, 31, 1498-1506. [CrossRef]

11. Klemm, W.; Heusinkveld, B.; Lenzholzer, S.; Van Hove, B. Street greenery and its physical and psychological impact on thermal comfort. Landscape Urban Plann. 2015, 138, 87-98. [CrossRef]

12. Kong, L.; Lau, K.; Yuan, C.; Chen, Y.; Xu, Y.; Ren, C.; Ng, E. Regulation of outdoor thermal comfort by trees in Hong Kong. Sustain. Cities Soc. 2017, 31, 12-25. [CrossRef]

13. Regulation of the Minister of Infrastructure of April 12th, 2002 on technical conditions to be met by buildings and their location. Available online: https:/www.global-regulation.com/translation/poland/ 3353940/regulation-of-the-minister-of-infrastructure-of-12-april-2002-on-technical-conditions\%252cwhich-should-correspond-to-the-buildings-and-their-location.html (accessed on 2 August 2019).

14. Borowski, J.; Pstragowska, M. The basic directions of shaping trees. In Techniques and Technologies for Green Areas, Urban and Rural Greenery- Contemporary and Historic; Drozdek, M.E., Wojewoda, I., Purcel, A., Eds.; Oficyna Wydawnicza Państwowej Wyższej Szkoły Zawodowej w Sulechowie: Sulechów, Poland, 2009; pp. 7-18. ISBN 978-83-60792-15-5. (In Polish)

15. MOJE DRZEWA.PL. Available online: http://www.drzewa.nk4.netmark.pl/atlas/klon/klon_zwyczajny/klon_ zwyczajny.php (accessed on 2 August 2019).

16. Online plant catalog, Acer pseudoplatanus. Available online: http://www.e-katalogroslin.pl/plants/235,klonjawor_acer-pseudoplatanus/ (accessed on 2 August 2019).

17. KLONY, Acer pseudoplatanus. Available online: http://www.klony.info/klony/klon/46 (accessed on 2 August 2019).

18. Seneta, W.; Dolatowski, J. Aceraceae. In Dendrologia, 4th ed.; Publishing Company PWN SA: Warsaw, Poland, 2012; pp. 352-372. ISBN 978-83-01-15369-4.

19. Armson, D.; Rahman, M.A.; Ennos, A.R. A comparison of the Shading Effectiveness of Five Different Street Tree Species in Manchester, UK. Arboric. Urban Forest 2013, 39, 157-164. Available online: joa.isa-arbor.com/ request.asp?JournalID=1\&ArticleID=3278\&Type=2 (accessed on 26 February 2019).

20. Błażejczyk, K.; Baranowski, J.; Błażejczyk, A. Forecast of changes in climate conditions in Poland up to 2100 year. In Climate Impact for Health in Poland: Current State and Forecast Until 2100; Puskarz, J., Przymanowska-Boniuk, D., Eds.; Wydawnictwo Akademickie SEDNO Spółka z o.o.: Warsaw, Poland, 2015; pp. 93-106. ISBN 978-83-7963-042-4. (In Polish)

21. Czerwieniec, M.; Lewińska, J. Aesthetic functions. Social, didactic, educational and economic functions of green areas. In Greenery in the City; Witkowska, J., Ed.; Institute of Spatial and Communal Economy: Cracow, Poland, 2000; pp. 45-49. ISBN 83-86309-11-3. (In Polish) 